\title{
Motivations of Organizational Citizenship Behavior's Altruism: Through the Perspective of Guanxi
}

\author{
Xiaotong $\mathrm{Yu}^{1}$ \\ ${ }^{1}$ School of Business Management \\ Yunnan University of Finance and Economics \\ Kunming, China \\ E-mail: yuxiaotong0523@sina.com
}

\author{
Bo Huang ${ }^{2} *$ \\ ${ }^{2}$ School of Business Management \\ Yunnan University of Finance and Economics \\ Kunming, China \\ E-mail: betty4870@126.com \\ * Bo Huang
}

\begin{abstract}
Despite the growing number of studies on the motivations of organizational citizenship behavior $(\mathrm{OCB})$ in work context, there are few studies which take Chinese culture into account such as guanxi. Based on literature review and theoretical analysis, authors discuss the motivations of $\mathrm{OCB}$ 's altruism from a perspective of guanxi in Chinese organizations and argue $\mathrm{OCB}$ can be triggered by altruistic or self-interested motivations that are produced by Confucianism and guanxi culture. By this way, it is necessary to provide reference to expand the future researches on $\mathrm{OCB}$ and improve the practice of management in Chinese context.
\end{abstract}

Keywords-guanxi; organizational citizenship behavior; altruism; self-interested motivations; Chinese context

\section{INTRODUCTION}

Under the influence of Chinese traditional culture especially the Confucianism, guanxi has a long history in China. It is the result of emphasis on ethics, which, in Chinese own organizations, has made guanxi so ubiquitous that it is often considered as the crucial and decisive factor in one's occupational success (Yeung and Tung, 1996) ${ }^{[1]}$, from an economic system so imperfect, and an admin istration so feeble. For the past two decades or more, an increasing research interest have been witnessed on the subject of Chinese guanxi in the field of organization behavior and human resource management (See Fig. 1.). It is mainly because guanxi plays an important role in organizational operations management. For example, inside the organization, if individuals can utilize their guanxi to benefit the organizations (which can be seen as altruistic results), they will have an opportunity for a promotion and rewards (which can be seen as selfinterested results) before performance appraisal. So, it is necessary to explain what are the real motivations propel employees to show citizenship behaviors and are their behaviors relevant to the cultural context such as guanxi.

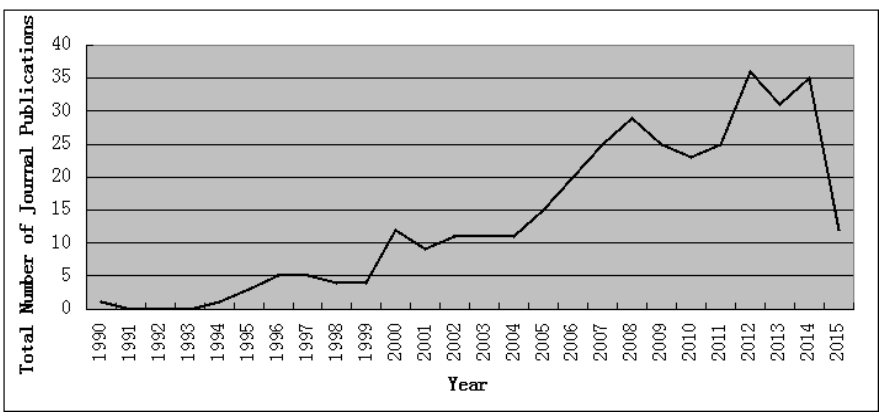

Figure 1. The number of guanxi papers published in journals from 1990 to 2015.

Most scholarly works on guanxi have tended to discuss its conception and dimensions, however, little researches have been focused on the effects of guanxi on behavioral motivations and its specific cultural aspects. Hence, this paper firstly presents briefly the conception and cultural connotation of guanxi and its relationship with altruistic behaviors, and then reviews the literature researches about organizational citizenship behavior in China and discuss es the effects of guanxi on OCB's altruis $m$ from a pers pective of motivations in an oriental culture. Finally, the paper points out that guanxi itself may not matter, the real problem is the using of guanxi. Based on this paper, the author aims to provide reference to expand the future researches on guanxi especially its double-edged effects and improve the guanxi practice of management in China by the reasonable mechanism design to adopt advantages and avoid disadvantages.

\section{GUANXI IN CHINA}

At present, China is going through from planned economy to market economy, from traditional agricultural society to modern industrial society featuring collectivistic orientation. So, the conception of guanxi appeared in ancient China and has continued to nowadays. In Confucian's period, "Who you know not what you know", this proverb can be interpreted as follows: "who you know" means to establish the personal relationship with the proper organizations or individuals for altruistic or selfinterested purpose, and this relationship refers to guanxi in Chinese; "what you know" means technical expertise which includes the price and quality of products and 
services. In modern society. Some people define this term as "drawing on connections in order to secure favors in personal relations and to fulfill personal objectives."(Luo, 1997; Wong et al., 2003) ${ }^{[2][3]}$. And some define the term as "the existence of direct particularistic ties between an individual and others."(Farh, et, al., 1998) ${ }^{[4]}$. Others define the term as "an informal connection between two individuals who are bounded by an implicit psychological contract to follow the social norm."(Chen and Chen, $2004)^{[5]}$. At the Modern Chinese Dictionary, guanxi is defined as:i) an interrelation of hu man beings; ii) the state of reciprocal things' influence; iii) connections or involvement.

Generally speaking, there are two kinds of typical perspectives on guanxi(Zhang and Wang, 2014) ${ }^{[6]}$. Firstly, a broad perspective which is self-centered. Fei Xiaotong said "Chinese social relations pattern is just like ripples when throwing a stone into the water. Under the influence of social network, everyone is in the center of the circles, and when someone touches one of these circles' ripples, he will be associated with them"[7]. Secondly, a narrow perspective which emphasizes bilateral ties. For example, Bolino's(1999) pioneering research found significant positive effect of guanxi tie strength on job searching in China $^{[8]}$. The result showed that both direct and indirect guanxi ties were used to obtain help from job-assigning authorities, but using indirect ties led to better jobs than using direct ties. In a word, guan xi is rooted in the Chinese traditional culture, which is the Confucianism-dominated (Zhang and Chen, 2013) ${ }^{[9]}$ and mixed with face or human feelings in our paper. A mbler (1994) deemed that face and human feelings are crucial elements, face of a group or family is highly regarded among individuals ${ }^{[10]}$; in other words, personal behavior should cater for organizations. It is everyone's duty to identify oneself with the organizations. Therefore, in order to keep one's face, one would do something on purpose to cater for others' preferences and these behaviors are altruistic. By doing so, one can set up certain images as well. Besides, human feelings can be seen as the reciprocal and implicit obligation. At the right time, people who are given face should return the face to others in some way. By following principles of human feelings, relations will be more and more close. Consequently, guanxi is a special cultural phenomenon in China, and it is necessary to distinct its connotations from western relationship (See Table 1).

TABLE I. DIFFERENCES IN GUANXI (OR RELATIONSHIP) BETWEEN CHINA AND THE WEST.

\begin{tabular}{|c|c|c|}
\hline Features & Chinese Guanxi & Western Relationship \\
\hline Foundation & Affective & Economic \\
\hline Link & AffectiveCommitment & Economic Weigh \\
\hline Role & Implicit & Explicit \\
\hline Scope & Elastic and Blurry & Specific and Definitive \\
\hline Motivation & Face & Win-win \\
\hline $\begin{array}{c}\text { Governing } \\
\text { Principle }\end{array}$ & $\begin{array}{c}\text { Custom, Convention and } \\
\text { Standard }\end{array}$ & Law and Rule \\
\hline Essence & $\begin{array}{c}\text { Universal social bond in } \\
\text { Chinese culture. }\end{array}$ & $\begin{array}{c}\text { Social network of } \\
\text { individuals. }\end{array}$ \\
\hline $\begin{array}{c}\text { Cultural } \\
\text { Situation }\end{array}$ & $\begin{array}{c}\text { Collectivism and } \\
\text { Consanguinity }\end{array}$ & $\begin{array}{c}\text { Individualism and } \\
\text { Contracted Society }\end{array}$ \\
\hline Transitivity & $\begin{array}{c}\text { Transferable and } \\
\text { Inheritable }\end{array}$ & $\begin{array}{c}\text { Limited transitivity and } \\
\text { Interruptable }\end{array}$ \\
\hline
\end{tabular}

\section{LITERATURE REVIEW OF OCB IN CHINA}

Originally, Katz and Kahn(1966) pointed out the importance of a class of innovative and spontaneous behaviors, which are beyond role requirements ${ }^{[11]}$ but essential for accomplishment of organizational functions. Following the pioneer research by Smith, Organ and Near et al (1983), this kind of behavior was later conceptualized as organizational citizenship behavior $(\mathrm{OCB})^{[12]}$, defined as "individual behavior that is discretionary, not directly or explicitly recognized by the formal reward system, and that in the aggregate promotes the effective functioning of the organization" (Organ, $1988)^{[13]}$. In recent years, western scholars have gotten greater progress and development than Chinese scholars both in theory and in practice. And most of the researches are heavily focused on connotation, dimension features and antecedent variables under the backgrounds of western culture. George(1997) pointed out that cultural factor played a crucial role in the formation of individual $\mathrm{OCB}^{[14]}$. Owing to the cultural difference in values between East and West, western researches cannot be mechanically applied to Chinese management practice. Consequently, combining the Chinese cultural to discuss OCB is becoming one of main tasks in the field of indigenous research. Although, Farh et al., (1997) have proposed about OCB on Chinese culture and social background ${ }^{[15]}$, most related researches were still based on the theories and methods derived from the West(Lin and Ho, 2010) ${ }^{[16]}$.

In the Chinese context, traditional culture with Confucianis $m$ as the backbone focuses on guanxi and emphasizes cooperation. Under the impact of this cultural thoughts and values, compared with the researches of OCB in western countries, how has the guanxi related to Chinese OCB is becoming necessary for to discuss the behaviors' motivations in China. And from the controversies of current researches, it is found that the key to look for the cause of employees' OCB is exploring actors' motivations and stakeholders' consciousness.

\section{GUANXI AND MOTIVATIONS OF OCB'S ALTRUISM}

\section{A. OCB and Its Guanxi Connotation}

What will be particularly interesting to attention is cultural anthropologis ts have observed that Chinese people as inseparable from his or her surrounding network(Hsu, $1971)^{[17]}$. Moreover, Chinese has the collectivistic orientation, which means that Chinese primarily attempt to establish and maintain a harmonious relationship with his or her social surroundings in daily work life (Farh, Zhong and Organ, 2004) ${ }^{[18]}$. Some researches have shown that a proper and interactive leader-member-exchange relationship has some positive effects such as enhancing OCB, job satisfaction and reducing withdrawal behavior of the subordinates(Aryee and Chen, 2006; Hackett, Farh, Song and Lapierre, 2003; Liang, Ling and Hsieh, $2007)^{[19][20][21]}$. As guanxi for practice, managers can employ support, care, protection and interactional justice to motivate their employees to enhance expressions of OCB. So the importance of guanxi in Chinese daily life suggests that some domains of Chinese OCB are likely to be related to guanxi at workplace, such as interpersonal harmony, compliance with social norms and altruism. The 
author suggests that the effects of OCB on work outcomes are related to guanxi. But the author does not think that the altruism's motivations, namely the origin of $\mathrm{OCB}$, are pure and selfless. Now, a statement about this question should be made from Confucianis $m$ and private purpose..

\section{B. Altruistic Motivation with Confucianism}

There are three basic hypotheses about the traditional OCB: i) The motivations of OCB are selfless and altruistic; ii) OCB promotes organization to operate efficient; iii) OCB is good for all staffs. In Chinese traditional culture, Confucianism is created in feudalistic society, and it is not only an important force to maintain public order but a tool that feudal ruling class used to safeguard themselves' regime (LV, 2014)[22]. Generally, in Confucianism, there are two essences, namely, jen as benevolence and li as decorum, which are the central thoughts of Confucianism regarding the manner of getting along with people(Lin and Ho, 2010)[23], which reflects the important status of this two essences on interpersonal interactions, especially in terms of the harmony of long-term orientation, altruism toward colleagues, and proper interpersonal relationship in organization. What Confucius does advocate is the conception of "ren"(benevolence) that refers to altruism. People have to implement obligations, undertake responsibilities and remove private interests. In addition, no one is allowed to benefit others for serving himself or herself purpose, and even they need to sacrifice their own happiness to seek benefit for others. So, the author suggests that the Chinese employees who are deeply influenced by Confucian culture will show the altruistic behavior and bring a positive effect on organization. And this viewpoint also get the literature supporting. Farh et al.(1997) found that based on Wu-Lun(five main guan xi in Confucianism), Chinese traditional organization performs well on the OCB.

\section{Self-interested Motivation with Private Purpose}

Based on discussion about the factors of guanxi such as face and human feelings, some questions are put forward on the traditional basic hypotheses in aspects of actors' motivations. Firstly, there are self-interested motivations and human feelings transaction hiding behind altruistic behaviors. For example, by helping others and participating in group activities, some employees aim to show they are more obliging and wise, thus, they can get more attention from others. And even in some cases they want to prove that they are better than others by some willful actions. Secondly, OCB can be seen as a strategy of impression management. Bolina once said, "A good solider may be a good actor"[24]. Some individuals show the citizenship behaviors, and they just want to leave a good impression to others so as to realize individual purpose rather than to feedback the organizations. In other words, employees utilize the objective and altruistic outcomes to build guanxi and eventually satisfy their selfinterested needs. For example, the more one's behaviors of altruism are, the more promotion opportunities they will have. Because this kind of people can leave an impression of "good soldier".

In this paper, the author discusses guanxi, on the one hand, through a perspective of altruistic motivation with Confucianism, can motivate responsible and effective performances on OCB. In order to enhance guanxi or be kind with others, one will perform more actively on work, and also maintain harmony on interaction with colleagues. On the other hand, when altruistic behaviors for selfinterested motivation purpose, OCB refers to face or human feelings and it can be seen the result of guanxi transaction.

\section{CONCLUSIONS}

So far, the author has reviewed the conceptions and connotations of guanxi and OCB in Chinese context. Along the way, what the author offers is not merely some suggestions as to how to advance research on the effects of guanxi on OCB, but implications for practice to Chinese managers.

First of all, OCB is a behavior of voluntary cooperation and it maintains the normal operation of organization. At any time and under any circumstances, managers enjoy its positive affects. For example, OCB can produce the contextual performance, achieve organizational aims, alleviate the conflict and enhance productivity. Secondly, some people act in ways to maximize their self-interests. Managers should consider a question about how they could penetrate the surfaces to see into the employees' state of mind. Moreover, guanxi is a double-edged sword. Managers need to have a full accounting of the relationship between OCB and in-role or extra-role behaviors. And on this basis, by designing the reasonable mechanism, adopt advantages and avoid disadvantages. Finally, cultural differences affect the OCB. Chinese managers should highlight the importance of collectivis $m$ and lead employees to be engaged in OCB more positively for altruistic purpose since group harmony, unity and loyalty are mainly focused on collectivism of Confucianism. In other words, altruism toward colleagues, harmony of longterm orientation and proper guanxi in organization reflect a behavior in conformity with Confucianism.

\section{REFERENCES}

[1] I. Yeung, and R. Tung, "Achieving business success in Confucian societies: The import ance of guanxi(connections)", Organizational Dynamics, vol. 25, 1996,pp.54-65.

[2] Y. Luo, "Guanxi: Principles, philosophies, and implications", Human Systems Management, vol. 16, 1997, pp.43-51.

[3] Y.Y. Wong, H.Y Ngo, and C.S. Wong, "Antecedents and out comes of employees' trust in Chinese joint ventures", Asia Pacific Journal of Management, vol. 20, 2003, pp. 481-499.

[4] J.L. Farh, A.S. Tsui, K. Xin, and B.S. Cheng, "The influence of relational demography and guanxi: The Chinese case", Organization Science, vol.9, 1998, pp. 471-488.

[5] C.C. Chen, and Y.R. Chen, "Guanxi practices and trust in management: A procedural justice perspective", Organizational Science, vol. 15, 2004, pp. 200-209.

[6] X.J. Wang, and H.Z. Wang, "A Literature Review of Chinese Guanxi in Management", Chinese Journal of Management, vol. 11, 2014, pp. 1087-1094.

[7] X.T Fei, From the soil: The foundations of Chinese society, first ed., Shanghai Guan Cha She, 1948.

[8] M.C. Bolino, "Citizenship and Impression Management: Good Soliders or Good Actors?", Academy of Management Review, vol. 24, 1999, pp. 82-98.

[9] S.S. Zhang, and J.X. Chen. "A Research on Guanxi in the Chinese Context from the Respective of Culture", Journal of Zhejiang Gongshang University, vol. 2, 2013, pp. 76-82.

[10] T. Ambler, "Marketing's Third Paradigm: Guanxi", Business Strategy Review, vol. 5, 1994, pp. 69-80. 
[11] D. Katz, and R.L. Kahn, "The Social Psychology of Organizations", vol.13, 1966.

[12] C.A. Smith, D.W. Organ, and J.P. Near, "Organizational Citizenship Behavior: Its Nature and Antecedents", Journal of Applied Psychology, vol. 68 , 1983,pp.653-663.

[13] D.W. Organ, Organizational Citizenship Behavior: The good solider syndrome, Lexington, Lexingt on Books, 1988.

[14] GA. Neuman, and JR. Kickul, "Organizational Citizenship Behaviors: Achievement Orientation and Personality", Journal of Business and Psychology, vol. 13, 1997, pp. 263.

[15] J.L. Farh, P.C. Earley, and S. C. Lin, "Impetus for Action: A Cultural Analysis of Justice and Organizational Citizenship Behavior in Chinese Society", Administrative Science Quarterly, vol. 42, 1997, pp. 421-444.

[16] L.H. Lin, and Y.L. Ho, "Guanxi and OCB: The Chinese Cases", Journal of Business Ethics, vol. 96, 2010,pp. 285-298.

[17] F.L.K. Hsu, "Psychological homeostasis and jen: conceptual tools for advancing psychological anthropology", American Anthropologist, vol. 73 ,1971, pp. 23-44.

[18] J.L. Farh, C.B. Zhong, and O.B. Organ, "Organizational Citizenship Behavior in the People's Republic of China", Organization Science, vol. 15, 2004, pp. 241-253.
[19] S. Aryee and Z.X Chen, "Leader-member exchange in a Chinese context: Antecedents, the mediating role of psychological empowerment and outcomes", Journal of Business Research, vol. 59, 2006, pp: 793-801.

[20] R.D Hackett, J.L Farh, L.J Song and L.M Lapierre, "LMX and organizational citizenship behavior: Examining the links within and across Western and Chinese samples" In G. Graen(Ed), Dealing with diversity: LMX leadership, 2003, vol. 1, pp: 219-263.

[21] S. Liang, H. Ling and S. Hsieh, "The mediat ing effects of leadermember exchange quality to influence the relationships between paternalistic supervisory and organizational citizenship behaviors", Journal of American Academy of Business, vol. 10, 2007, pp:127137.

[22] C. Lv, "Confucianism and Art of Leader in Enterprise Management” , Manager's Journal, vol. 11, 2014, pp: 6-7.

[23] L.H. Lin and Y.L. H, "Guanxi and OCB: The Chinese Cases", Journal of Business Ethics, vol. 96, 2010, pp: 285-298.

[24] M.C. Bolina, "Citizenship and Impression Management: Good Solider or Good Actors?", Academic of Management Review, vol. 24, 1999, pp. 82-98. 